\title{
Modeling and Buckling Analysis of Rectangular Plates in ANSYS
}

\author{
Ahmed Hassan Ahmed Hassan ${ }^{a^{*}}$, Naci Kurgan ${ }^{b}$ \\ ${ }^{a, b}$ Ondokuz Mayis University, Faculty of Engineering, Department of Mechanical Engineering, Samsun, Turkey. \\ E-mail address: $15210457 @$ stu.omu.edu.tr ${ }^{a^{*}}, \underline{\text { naci.kurgan@ omu.edu.tr }}^{b}$
}

ORCID numbers of authors:

0000-0002-4880-0184 ${ }^{a^{*}}, 0000-0001-7297-7249^{b}$

Received date: 22.02 .2019

Accepted date: 19.04 .2019

\begin{abstract}
With plate-buckling problem still being an active area of research in the field of mechanics of materials, researchers need to validate the proposed solutions and theories, using analysis tools such like ANSYS, which is a robust general-purpose finite element analysis tool. This article investigates modeling and buckling analysis of rectangular plates in ANSYS® Mechanical APDL, Release 17.1, through a series of comparative studies conducted on various models and options. Shell and solid models of homogeneous and functionally graded plate (FGP) using various elements are investigated. Expressing boundary conditions on both shell and solid models of plate for buckling analysis is discussed. Procedures of buckling analysis in ANSYS are presented and effects of meshing, boundary conditions and element options are examined though comparative studies. Results obtained from ANSYS are compared to various analytical solutions.
\end{abstract}

Keywords: Plate buckling; ANSYS; functionally graded; shell models; solid models.

\section{Introduction}

Reddy defines plate as: "A plate is a structural element with planform dimensions that are large compared to its thickness and is subjected to loads that cause bending deformation in addition to stretching [1]". Plate may be rectangular, square, circular, skew or any other geometry with or without holes. Due to its relative simplicity and wide application, rectangular plate is usually used to illustrate the plate definition [1-4]. A rectangular plate is shown in Fig. 1 with typical coordinate system and names of characteristic dimensions. Normally, the length of the plate is referred to as (a) and the width is referred to as (b) while the thickness is referred to as (h).

In the applications that flat plate experiences in-plane compression, buckling phenomenon may occur. Buckling of a plate is defined as the loss of its stability under compressive loading [5]. Loss of stability means that shape of the buckled structure changes into a different configuration when the loads reach a critical value. Buckling occurrence depends on the shape of the structure, properties of the material, loading configuration and boundary conditions. Different bodies buckle in different ways. Flat plates experience bifurcation buckling, aka classical buckling [2]. Many analysis procedures have been proposed to solve the problem of plate buckling. One of 
the most used method in structural engineering is the finite element analysis (FEA). That is due to its profound theory and its ability to analyse complicated geometries and include nonlinearities. ANSYS ${ }^{\circledR}$ provides a ready-to-use general-purpose FEA software that has the capability of coupling different analysis fields. A plate can be modeled in ANSYS in many ways.

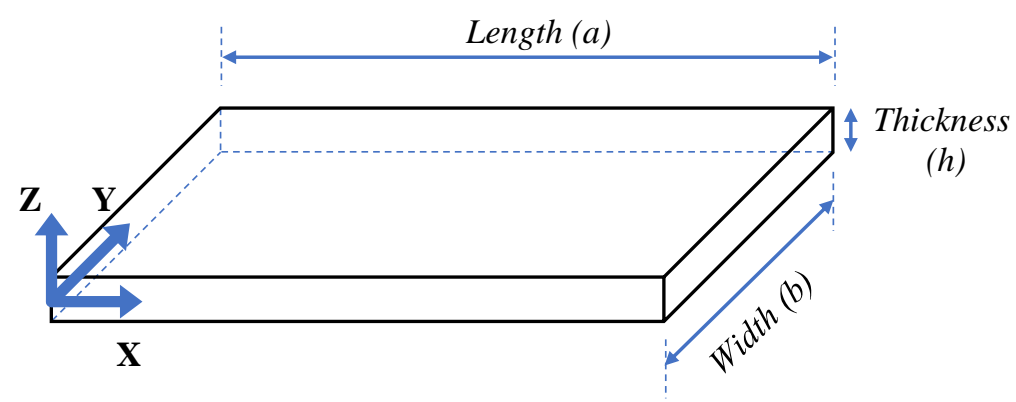

Fig. 1. Rectangular plate structure

Countless articles use ANSYS for performing buckling analyses on plates as a verification step for their presented methods, but with no intension to share the models, options or steps used in the ANSYS analysis. Few articles consider sharing or conducting whole research on models and options of specific analysis type within some analysis software. An example for such efforts is the recently published article by Mercan [6], who presented a demonstration of how to mesh and prepare micro and nano sized structures using some analysis software package.

This article investigates plate modeling and buckling analysis and compares models to each and to plate theories aiming at being a reference that guides researchers in choosing plate models for buckling analysis. Effects of mesh size, number of layers and options of elements are also presented. In literature, various plate models in ANSYS are compared based on modal and stress analyses; but there is no reference found that could be a guide for researchers to conduct buckling analysis on rectangular plates in ANSYS. This kind of reference exists only for stress and modal analyses. Banerjee [7] compared between a plate models of shell elements and solidshell elements for stress analysis. Wang [8] compared between plate models of shell, solid and solid-shell elements for stress and modal analysis. For buckling analysis, Swamy [9] presented buckling of rectangular plate using legacy planar element. Buckling of cylindrical thin-walled structures was presented by Subramani [10], who compared between two shell models, and Bischoff [11] who compared a shell and a solid models in ANSYS.

This article presents rectangular plate modelling and buckling analyses in ANSYS. Effects of mesh size, number of layers and options of elements are also presented. The process of obtaining results from analyses of many different models was automated using APDL, which is a scripting language that can be used within ANSYS [12]. The version of ANSYS used in this research is ANSYS ${ }^{\circledR}$ Mechanical APDL, Release 17.1.

\section{ANSYS elements used in plate models}

ANSYS provides wide range of groups of elements covering many simulation fields. For rectangular plate models, shell, solid and solid-shell elements are used in this article. 


\subsection{Shell elements}

Shell elements that are suitable to model rectangular plates are Shell181 [13] and Shell281 [14]. Shell elements simulate the concept of plate/shell theories, which reduce the plate problem to surface model with strain/deformation assumptions through the thickness. Structural shell elements available in ANSYS are based on first-order shear-deformation theory (FSDT), and they can model homogeneous as well as laminated plates by using the ANSYS command SECDATA [15].

\subsection{Solid elements}

Solid elements are used to model the plate as three-dimensional solid body. Although using these elements seems to be modeling the exact plate, it experiences "locking" problems when simulating thin plates. Locking phenomenon is related to the finite elements methods, makes the model behave different from what it should be [1]. Therefore, using solid elements in modeling thin plates should be associated with some treatment of the results. Solid structural elements in ANSYS can be classified into tetrahedral and brick elements.

\subsubsection{Tetrahedral elements}

Tetrahedral elements include Solid285 [16] and Solid187 [17]. Tetrahedral elements have a high capability to model irregular meshes. These elements can be used to model homogeneous plates, but there is no ready tool to model laminated plates using these elements in ANSYS. One have to assign different materials to different layers through thickness, or glue different adjacent volumes of different materials together in order to model a laminated plate.

\subsubsection{Brick elements}

Brick elements include Solid185 [18] and Solid186 [19]. In their brick form, they lack the high capability of tetrahedral elements of modeling irregular meshes. However, for regular geometry, they provide more accurate results than tetrahedral elements. Laminated plates can be modeled as adjacent layers of brick elements assigned with different materials. In addition, brick structural elements provided by ANSYS have the ability to be associated with a shell section; meaning that different materials can be assigned to different sections through the thickness of a plate by using the ANSYS command SECDATA. Therefore, laminated plates can be also modeled directly using available section commands in ANSYS.

\subsection{Solid-shell element}

There is only one solid-shell element provided in ANSYS; called Solsh190 [20]. Solid-shell elements are relatively a recent technology that intends to combine the benefits of solid elements and shell elements at once. Solsh190 is a brick structural element with the ability to include strain assumptions, which are intended to prevent various forms of locking phenomenon when modeling thin plates while being able to model thick plates accurately as well.

\section{Boundary conditions}

Boundary of a plate, i.e. edge, may have free, clamped or simply supported boundary condition [1]. Other less common boundary conditions include hinged, fixed and sliding edges. For buckling analysis, boundary conditions have to allow displacement at least in the direction in 
which load acts. Main boundary conditions of a plate under buckling analysis should interrupted as follows:

a) Free edge (F): is not geometrically restrained in any way.

b) Simply supported edge (SS): is free to have inplane displacements and rotates freely about its axis. This is the basic meaning of simply supported edge. Additional conditions might be added to this boundary condition, like being inextensible or immovable, also called SS-1 and SS-2, respectively.

c) Clamped edge $(\mathbf{C})$ : is free to have only inplane displacements.

d) Fixed edge: is a fully restrained edge. Neither rotations nor displacements are allowed.

Modeling geometry and boundary conditions of a rectangular flat plate for buckling analysis in ANSYS is discussed as follows.

\subsection{Modeling plate and boundary conditions in ANSYS}

In ANSYS, plate can be modeled as shell model or solid model. Boundary conditions expressed as displacement constraints, i.e. essential primary boundary conditions. Depending on the considered plate model, boundary conditions may be expressed as follows.

\subsubsection{Shell models}

Shell models are based on the shell elements Shell181 or Shell281. Plate shell model is an area meshed into smaller areas of shell elements. Shell elements have translation (UX, UY and UZ) and rotation (ROTX, ROTY and ROTZ) degrees of freedom at their nodes. Two important notes have to be considered about the implications of boundary conditions on those degrees of freedom. Firstly, rotation of edge about the thickness direction (UZ) is actually the inplane displacements (UX and UY). Therefore, restraining of ROTZ implies restraining of inplane displacements In other words, if inplane displacements (UX and UY) are to be allowable, ROTZ has to be allowable too. Secondly, rotation of edge about an inplane axis perpendicular to the edge actually means the out-of-plane displacement. Fig. 2 shows various boundary conditions expressed on shell model of a plate with two edges simply supported, one clamped and the last is free.

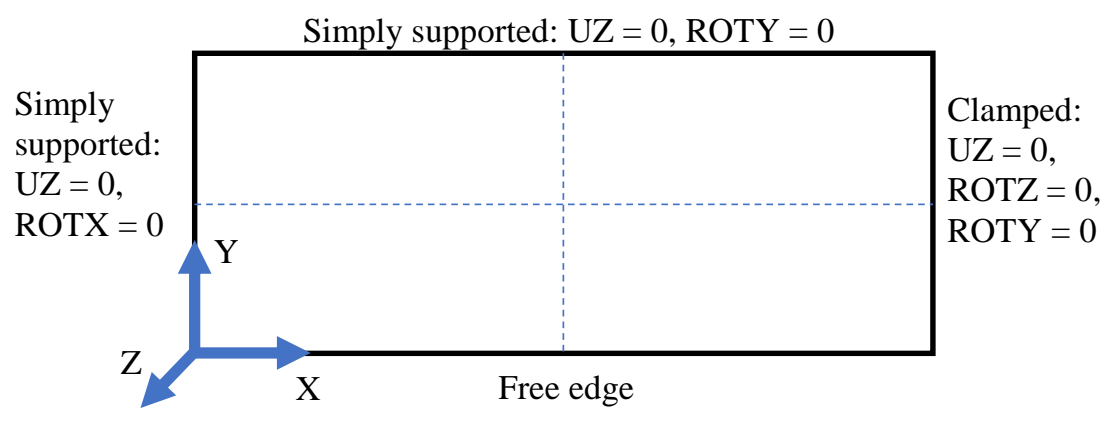

Fig. 2. Boundary conditions on shell model of plate

\subsubsection{Solid models}

Solid models are based on solid or solid-shell elements (Solid185, Solid186, Solid187, Solid285 or Solsh190). Plate solid model is a solid body meshed into small volumes of solid elements. Solid elements have only translation (UX, UY and UZ) degrees of freedom at their nodes. Boundary conditions on solid model are expressed on faces of the edges. For instance, simply 
supported edge in solid model is an edge that all nodes on the face of that edge have no lateral displacement allowed. Since no rotational degree of freedom available for solid elements, clamped boundary condition is expressed by coupling all nodes on the clamped edge's face in its normal direction. This prevents the edge from rotating around its axis. Fig. 3 shows various boundary conditions expressed on solid model of plate.

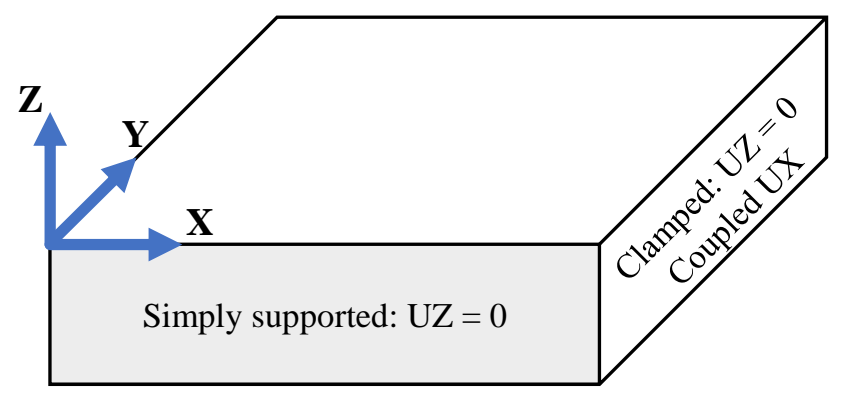

Fig. 3. Boundary conditions on solid model of plate

\subsection{Plate model symmetry and anti-symmetry}

Although some plate problems may have symmetry/anti-symmetry in geometry, loads and boundary conditions, expression symmetry/anti-symmetry in ANSYS for plate buckling analysis has to be done with attention. When imposing symmetry/anti-symmetry in the analysis, some buckling modes may be missed because only symmetric/anti-symmetric modes will be calculated. Therefore, it is advisable to work with full model whenever possible to ensure that no buckling mode has been missed. Fig. 4 shows full and symmetry models of a fully simply supported plate, i.e. all edges are simply supported, under uniaxial uniform pressure $\mathrm{P}$ expressed as load per unit length of the edge.

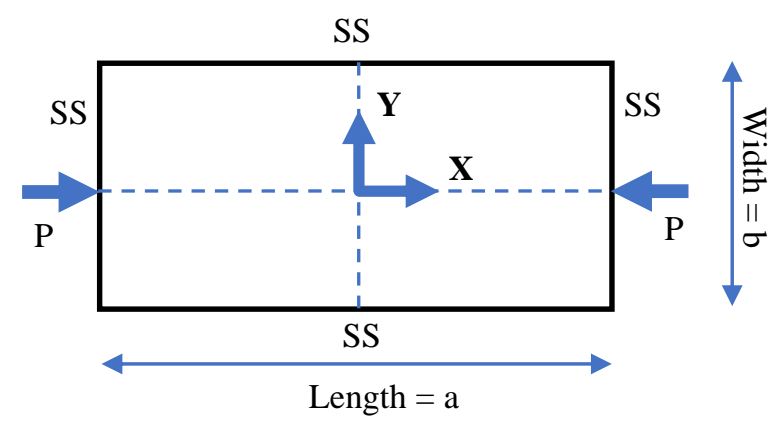

a) Full model

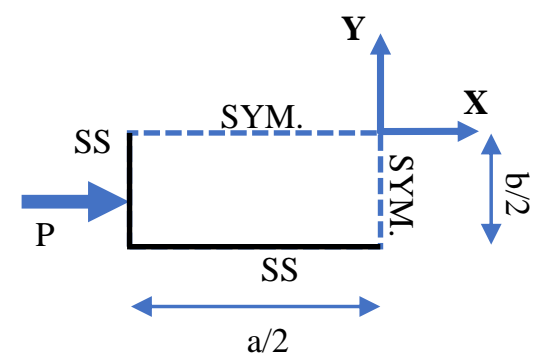

b) Symmetry model

Fig. 4. Full (a) and Symmetry (b) models of simply supported plate under uniaxial pressure

To further illustrate the behavior of symmetry model compared to full model a thin plate of length $1.5 \mathrm{~m}$, width $1 \mathrm{~m}$, and thickness $2 \mathrm{~mm}$ under uniaxial uniform pressure acting on the shorter edges, is modeled as full plate Fig. 4-a, and as symmetry model Fig. 4-b and linear eigenvalue buckling analysis is conducted. Elasticity modulus is assumed as $70 \mathrm{GPa}$ and Poisson's ratio as 0.3 . As shown in

Fig. 5, by using symmetry model ANSYS calculated first buckling load as $2.378 \mathrm{~N} / \mathrm{mm}$, while for the full model the first buckling load is calculated as $2.199 \mathrm{~N} / \mathrm{mm}$ as shown in 
Fig. 6-a. Here the symmetry model has missed the first buckling load. The buckling load calculated using the symmetry model is actually the second buckling load for the full model as shown in

Fig. 6-b.

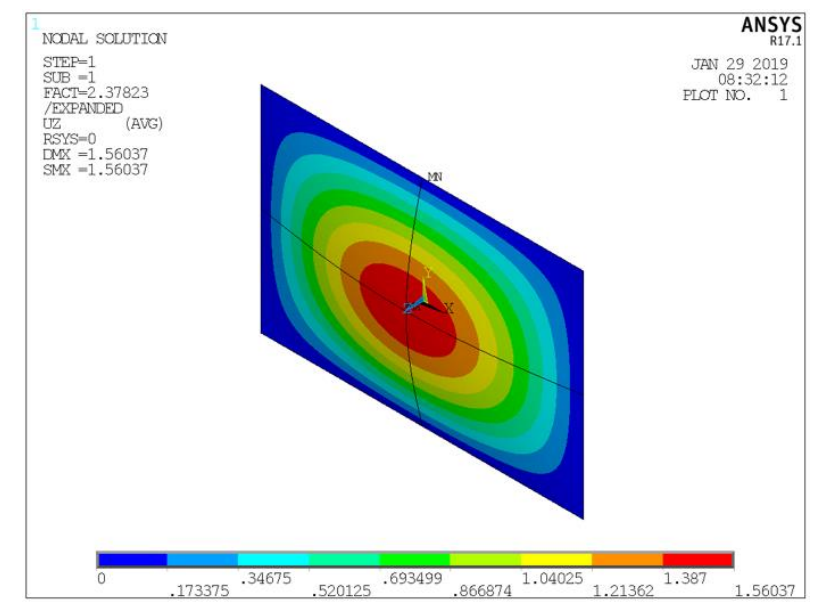

Fig. 5. First buckling mode of the symmetry model, buckling factor $=2.37823$

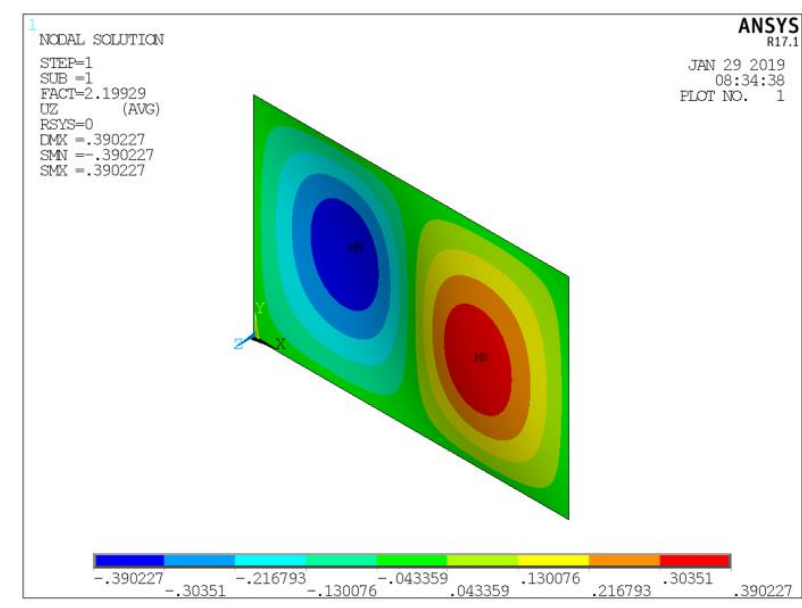

a) $1^{\text {st }}$ buckling mode, buckling factor $=$ 2.19929

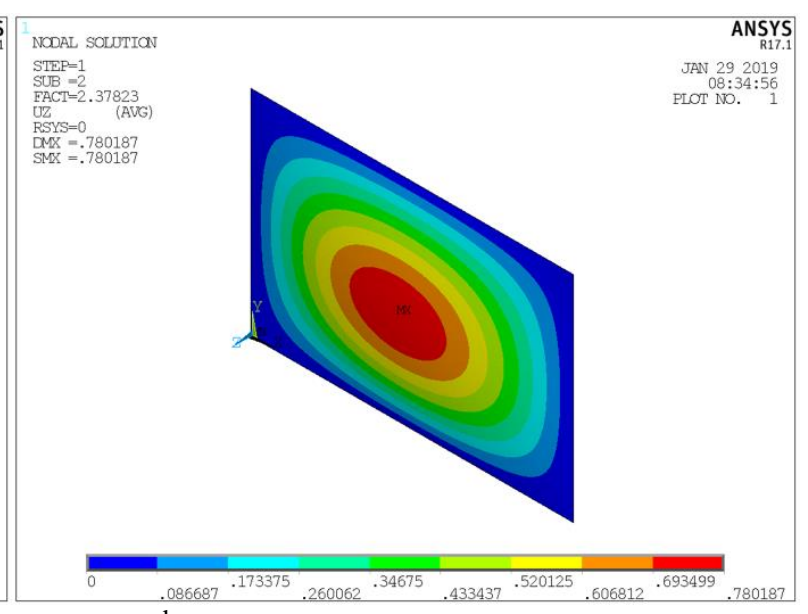

b) $2^{\text {nd }}$ buckling mode, buckling factor $=$ 2.37823

Fig. 6. First (a) and second (b) buckling modes of the full model

\subsection{Additional consideration for boundary conditions in ANSYS}

In spite of plate being under balanced forces, the model may need additional boundary conditions to restrain the rigid body translation and rotation. For example, for a full plate model with all edges being simply supported, additional constrains need to be added in order to prevent rigid body movement. In general, constraining of two different points in the plate should be enough to achieve prevention of rigid body movement under any loading/boundary conditions configuration. 


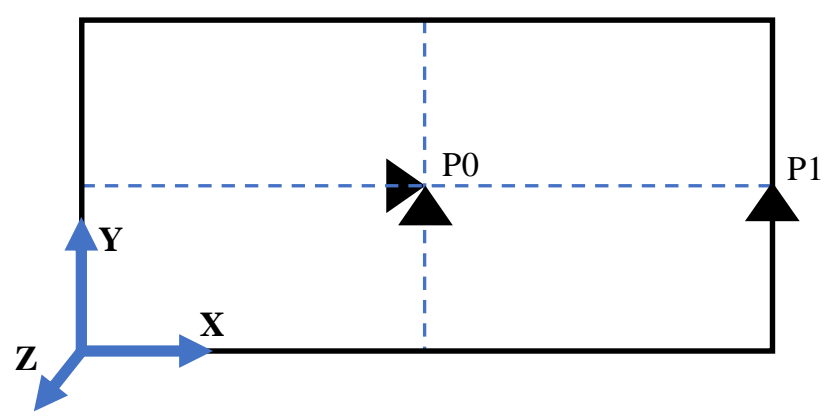

Fig. 7. Additional conditions for full shell model of plate

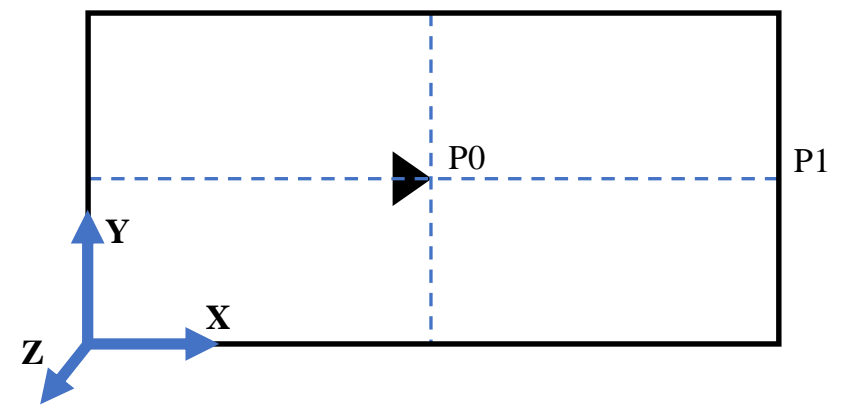

Fig. 7 shows a typical configuration of additional constraints for a full shell model. Point P0 is restrained in $\mathrm{X}$ and $\mathrm{Y}$ directions, while point $\mathrm{P} 1$ is restrained in $\mathrm{Y}$ direction.

\section{Buckling analysis in ANSYS}

In ANSYS, buckling analysis might be conducted using Eigenvalue buckling analysis or nonlinear static analysis [21]. Eigenvalue buckling analysis reveals the buckling load factor that has to be multiplied by the applied loads to reach buckling point [22,23]. Eigenvalue buckling analysis may be based on linear or nonlinear static analysis. Linear eigenvalue buckling analysis deals with ideal elastic structure and provides a non-conservative estimation that is useful for later complicated nonlinear buckling analyses. ANSYS provides a ready-to-use tool for eigenvalue buckling analysis and calculates buckling load factor along with buckling mode shapes. Note that displacements shown by ANSYS in these analyses have no physical meaning by themselves, and they are only useful in showing the buckling mode shape.

The second way to conduct buckling analysis in ANSYS is through a nonlinear static structural analysis $[24,25]$, which is a static analysis with large displacement option enabled. Plate is put under incremental load that is greater than estimated buckling load, and then the load-deflection curve is examined for the bifurcation point. The bifurcation point is the point at which the response (deflection in lateral direction, UZ) suddenly changes more rapidly, i.e. buckling point. Various nonlinearities and imperfections can be included in the nonlinear analysis. Attention must be paid when conducting buckling analysis of homogeneous or symmetric laminated plate under only inplane loads; because buckling behavior would not captured by ANSYS. In this case, initial imperfection is needed to establish a deflection that will then get increasing with the increasing load and monitored for the buckling point. This initial imperfection is expressed usually as initial deformation obtained from previous static analysis for the plate under lateral loads, or from buckling mode shape resulted from previous buckling analysis. The imposed initial imperfection has to be small enough in order to obtain a curve with noticeable bifurcation point. Fig. 8 compares two load - lateral displacement (UZ) curves, 
i.e. load-deflection curves, of the mid-point of a plate, resulted from nonlinear statics structural analysis under same boundary conditions and loads with two different initial deflections.

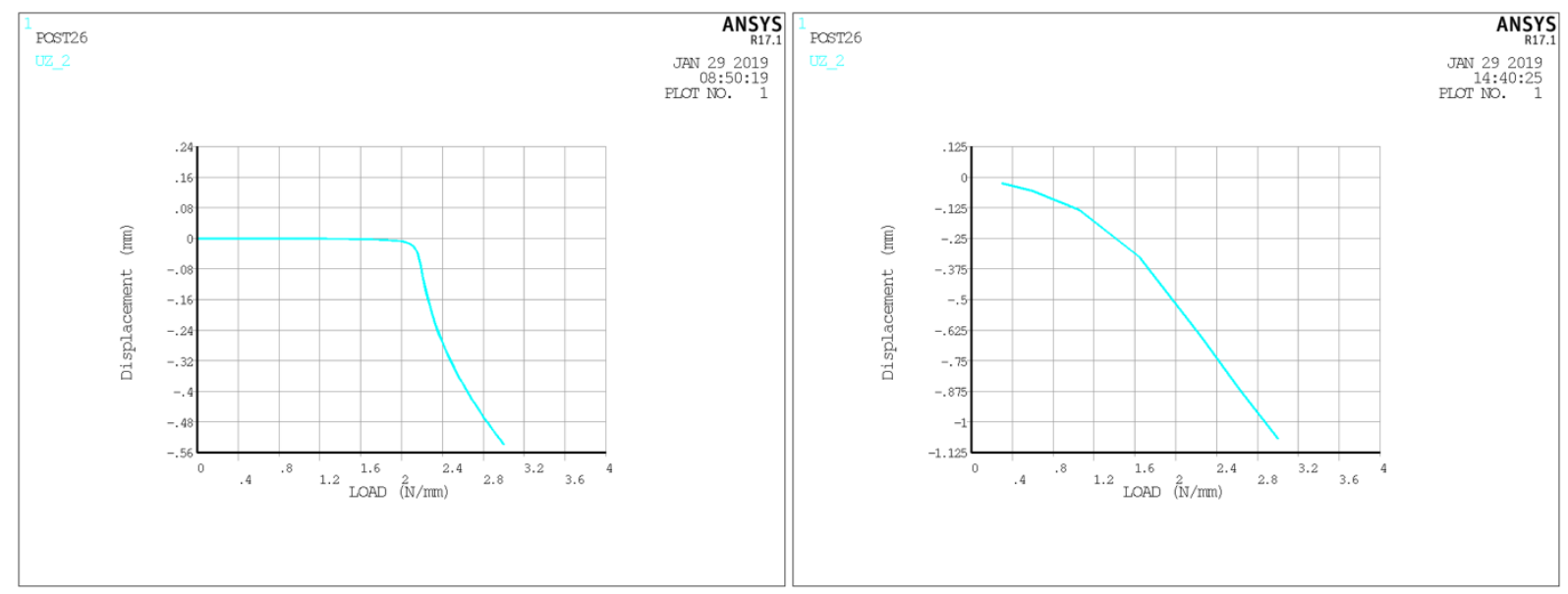

a) Small initial deflection

b) Large initial deflection

Fig. 8. Load-Lateral Displacement curves of plate with (a) slight and (b) larger initial deflection

Results shown in Fig. 8 are for a plate of $1.5 \mathrm{~m}$ length, $1 \mathrm{~m}$ width and $2 \mathrm{~mm}$ thickness, with 70 GPa elasticity modulus and 0.3 Poisson's ratio, under uniaxial uniform pressure acting on the shorter edges. Initial deflected geometries were obtained from previous linear eigenvalue buckling analysis, shown in

Fig. 6-a with updating geometry using UPGEOM [15] ANSYS command with small factor for the first analysis, and relatively larger factor for the second. For the first case, a bifurcation point can be observed through its load-deflection curve, while this is not the case for the second. By checking Fig. 8-a, it can be seen that buckling load is roughly $2.2 \mathrm{~N} / \mathrm{mm}$, which is same as the one obtained using eigenvalue buckling analysis tool that shown in

Fig. 6-a. Imposing even smaller initial deflection leads to clearer bifurcation point.

\section{Meshing}

Finite element analysis (FEA) is based on the concept of discretization of the region of the problem to smaller simpler elements; which are then solves and reassembled obtain a solution of the problem. This discretizing process is called meshing. Mesh size affects the accuracy of the solution. When modeling a plate in ANSYS, as in every FEA tool, one must decide a suitable mesh size for the elements. Smaller mesh size generates more elements and results that are more accurate may be generated. However, larger number of elements also increases required time to solve the problem. In this article, the term of mesh size is used to describe the inplane meshing, while number of layers is used to describe number of solid elements or shell sections through thickness. Accuracy of the buckling analysis in ANSYS is examined here for various values of mesh size, number of layers and various boundary conditions. Effects of inplane meshing and various boundary conditions on the linear eigenvalue buckling analysis in ANSYS is examined using shell models. Then effects of number of layers in the model is examined for functionally graded plates (FGP) using shell models, and for homogeneous plate using solid models with various element options. 


\subsection{Inplane mesh size}

Shell models are implemented here to illustrate how inplane mesh size affects accuracy of buckling analysis in ANSYS for plates with various aspect ratios and thickness. Fig. 9 compares shell models of Shell181 and Shell281 elements, with various values of inplane mesh size, expressed as elements per plate edge, and various values of thickness, expressed as side-tothickness ratio ranging from thin to moderately thick plates. Shell models used here are full models, i.e. with no symmetry expressed, as the one shown in Fig. 4-a. Plotted results are the error between buckling load obtained by ANSYS to those obtained using analytical solutions based on first-order shear-deformation theory (FSDT) as presented by Reddy [1], with a transverse shear-correction factor of 0.8925 .

Results show that using smaller mesh size, i.e. larger number of elements per edge, gives higher accuracy solutions for different side-to-thickness ratios $\mathrm{b} / \mathrm{h}$. However, gain in solution accuracy reduces, as mesh size gets smaller. As seen in Fig. 9 for Shell181 model, for each side-tothickness ratio, mesh size of 80 and 100 elements per edge provide almost the same solution; furthermore, 40 and 100 elements per edge have no significant difference in their solutions. Accuracy of Shell181 models seems to be more sensitive to the meshing size than the Shell281 models. Models of Shell281 provide solutions that are more accurate and closer to each other for various values of mesh size.

Another way to express mesh size is as element length that is independent of dimensions of the plate's edge. Fig. 10 shows solution accuracy of buckling analysis using Shell181 and Shell281 models of plate for various aspect ratios, i.e. plate's length-to-width ratio $a / b$, with a fixed element length. Accuracy is expressed as percentage error between ANSYS solutions and FSDT solutions. By using the same element length, larger plates, i.e. wider and/or longer, will contain more elements, which leads to results that are more accurate. Solution accuracy increases with increased number of elements, but at some point, it stops getting significantly better.

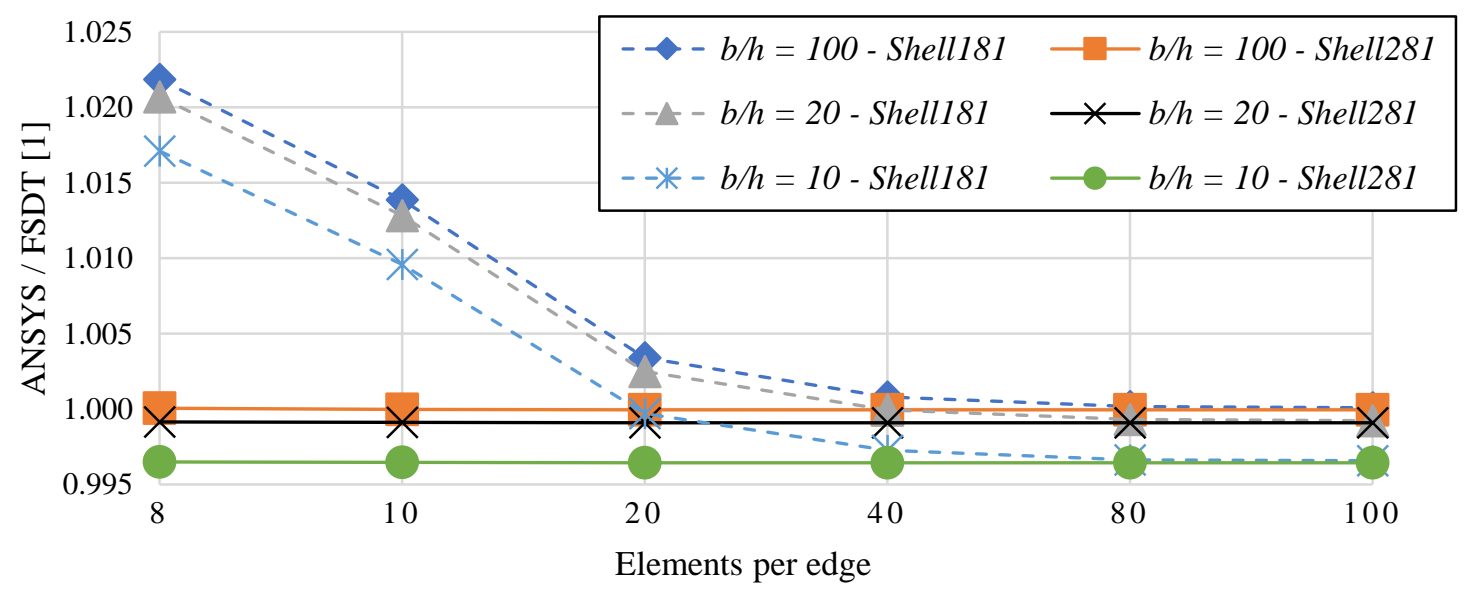

Fig. 9. ANSYS buckling solutions using shell models compared to FSDT [1] for various inplane mesh sizes and thickness values 


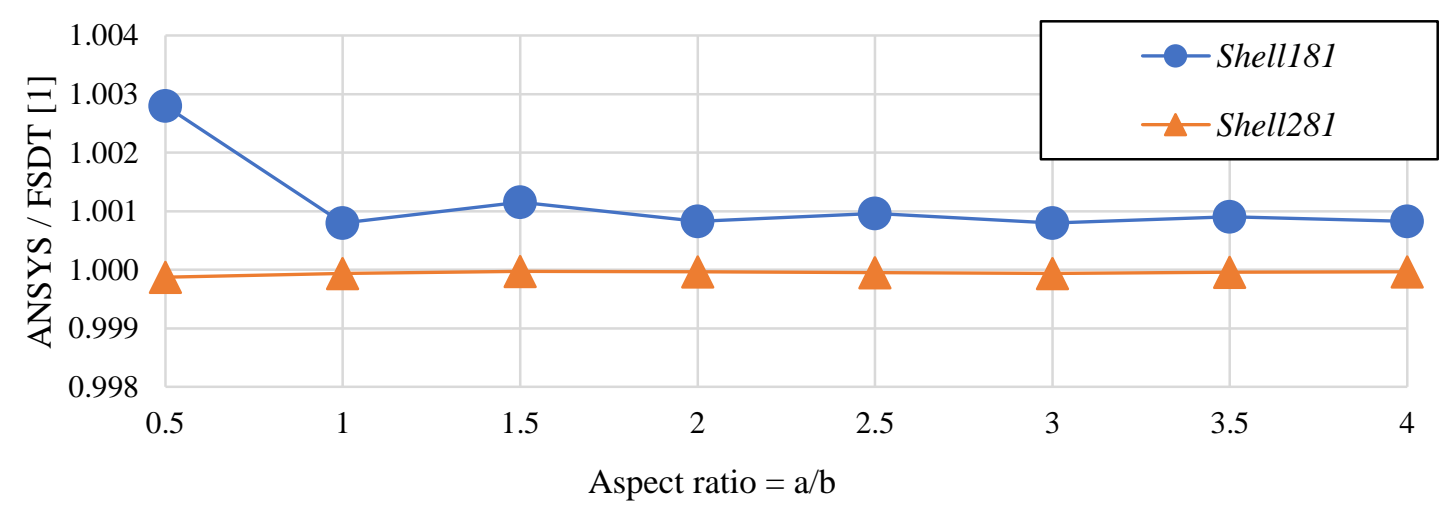

Fig. 10. ANSYS buckling solutions using shell models compared to FSDT [1] for various aspect ratios with fixed element length

The oscillation of solutions quality reflects the effect of the plate's aspect ratio. As a conclusion, even with the existence of variation in accuracy due to thickness of the plate, aspect ratio and mesh size, buckling loads calculated using both Shell181 and Shell281 models are very close to the FSDT solutions, while Shell281 is more accurate and less sensitive to aspect ratio and number of elements.

\subsection{Number of layers in shell model (FGP application)}

Functionally graded materials (FGMs) are advanced inhomogeneous composite materials in which graded interlayer separates different materials of the composite structure [26, 27]. FGM's concept is to replace the sudden change in structure that occurs at the interface between different materials, with a compositionally graded phase, aiming at reducing stress concentrations through the structure [26]. This microstructure variation in FGM occurs with a specific function through one or more dimensions of the volume. Modeling the properties variation through one or more dimensions of functionally graded plate (FGP) in ANSYS could be accomplished using many methods. For instance, one method is using dummy thermal loads [28]. However, when the FGP has its properties variation only through its thickness, it becomes more convenient to stack layers with desired properties to present the FGP.

For shell models, number of layers means number of defined sections through thickness. ANSYS provides SECDATA command to define those sections and the relative thickness, material and orientation of each. Effect of number of layers on accuracy of shell model for buckling analysis is presented here. For shell model of homogeneous plate, number of layers does not alter the results. Therefore, to illustrate their effect on shell model accuracy, a composite plate is needed. A plate of functionally graded material (FGP) is modeled using shell elements and examined here.

Modeled FGP is a ceramic-metal composite plate, with elasticity modulus E varying linearly through its thickness and constant Poisson's ratio. Elasticity modulus of ceramic assumed as $\mathrm{E}_{\mathrm{c}}=380 \mathrm{GPa}$, for the metal as $\mathrm{E}_{\mathrm{m}}=70 \mathrm{GPa}$ and Poisson's ratio as $v=0.3$. Aspect ratio $\mathrm{a} / \mathrm{b}$ is taken as 0.5 . Results are compared to solutions based on third-order deformation theory (TSDT) presented in the work of Shariat [29].

Fig. 11 shows the buckling load obtained by ANSYS for FGP shell model of Shell281 elements compared to TSDT solutions, for various number of layers. Side-to-thickness ratio b/h is taken as 10. Results show that using small number of layers results in under-estimated buckling load. At the range of low number of layers, increasing the number of layers has significant effect on 
the calculated buckling load, but at some point, change in results due change in number of layers starts to vanish. Although, it is often desired to have as many layers as possible to simulate the continuous variation in FGPs, models with very large number of layers consume long time in analysis, while not providing significantly different solutions than those with reasonably lower number of layers. For example, in the case shown in Fig. 11, model with 60 layers provides solution that is just slightly lower than the solution of model with 180 layers. Therefore, number of layers should be selected wisely to obtain accurate enough results with reasonable analysis time.

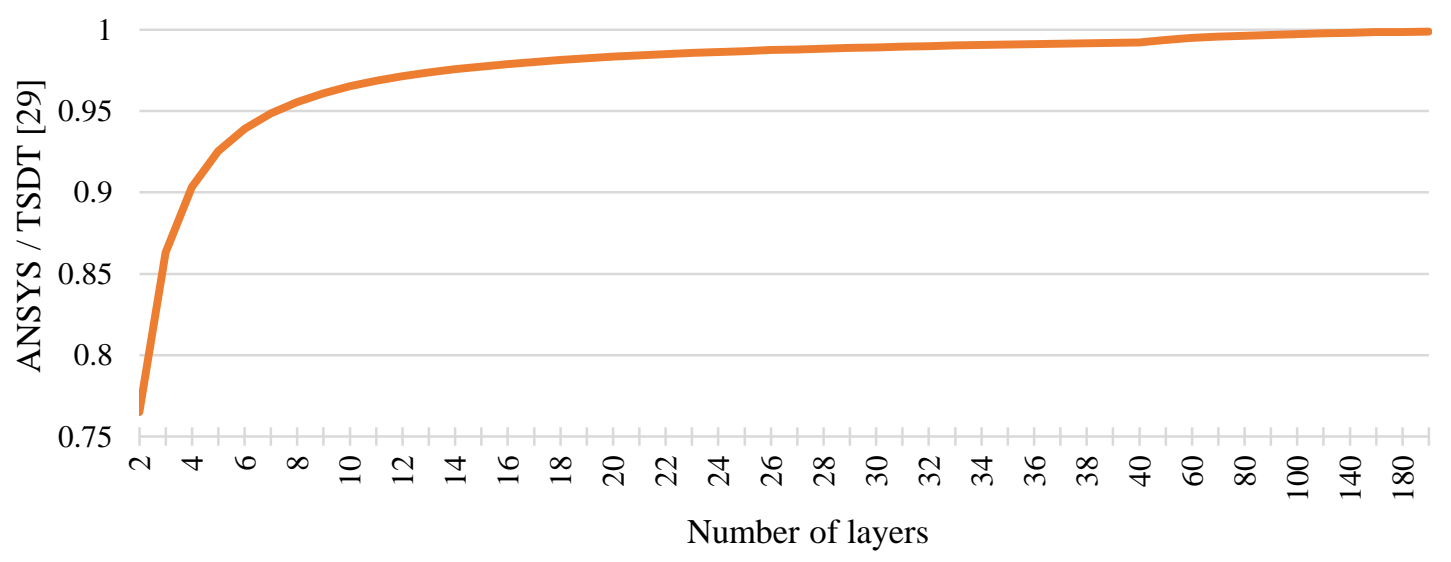

Fig. 11. ANSYS buckling solutions of FGP model of layered shell element compared to TSDT [29] for various number of layers

\subsection{Options of shell elements}

ANSYS provides options for elements to be tweaked in order to obtain better models for various applications. Among shell elements, Shell181 has two interesting options to set. The first is the full integration option $(\operatorname{KEYOPT}(3)=1)$, and the second is the advanced curve formulation option $(\operatorname{KEYOPT}(5)=1)$. Effects of these options on the accuracy of buckling analysis are shown in Fig. 12. Shown analyses are conducted using the same plate model with the same element length. Therefore, reduced accuracy with increased aspect ratio is expected. It is observed that enabling option of full integration and/or advanced curve formulation slightly reduces the solution accuracy. However, both options reveal solutions those are very close to each other.

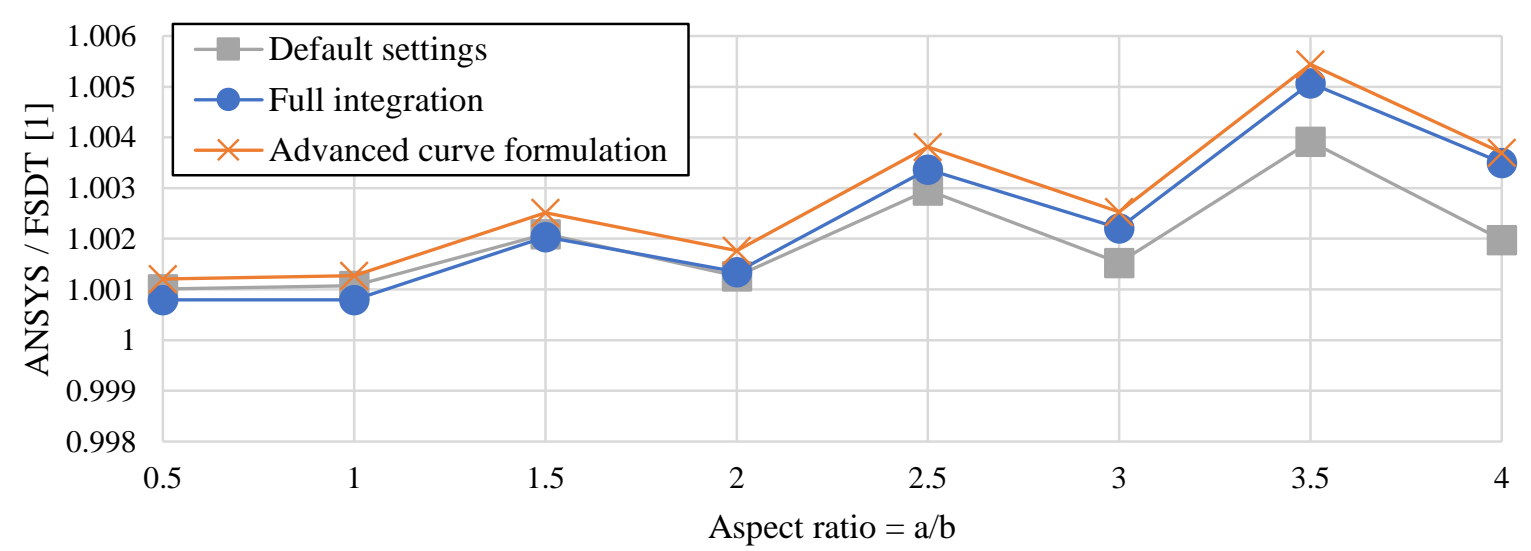

Fig. 12. ANSYS buckling solutions using Shell181 model compared with FSDT [1] for various options of element technology and aspect ratios 


\subsection{Number of layers in solid model}

Plates can be modeled as three-dimensional body using solid or solid-shell elements. In solid models, in addition to the inplane meshing one has to set the out-of-plane meshing even for homogeneous plates. Meshing through the thickness of the plate is expressed as number of layers. This section examines the effect of number of layers in solid model of a fully simply supported square plate $(a=b=1 \mathrm{~m})$ under uniaxial pressure for the same fine inplane element size and various values of plate's side-to-thickness ratios. ANSYS solutions obtained using various solid elements are compared to those obtained using FSDT theory presented by Reddy [1]. In addition, various elements' options are examined. Solid models used in the following analyses are symmetry models, as the one shown in Fig. 4-b.

\subsubsection{Tetrahedral solid elements}

Because of their shape, number of layers could not be set directly. Instead, plate is created by gluing as many thinner meshed plates as the demanded number of layers. Gluing operation in ANSYS is done using VGLUE [15] command. Steps of modeling plate as glued volumes are shown in Fig. 13. Each of these thinner plates can be assigned with different material properties in order to model composite plate. The case of homogeneous plate modeled with glued multilayers is studied below.

Solutions of linear eigenvalue buckling analysis of plate modeled using tetrahedral solid elements compared to FSDT solutions are shown in Fig. 14-(a and b) for various number of layers and side-to-thickness ratios. Results show that plate model of Solid187 elements seems to provide same solutions regardless of number of the layers. The other tetrahedral element Solid285 does not provide right results for buckling analysis for small number of the layers, while being impractical to conduct the analysis with larger number of layers due to the long time consumption. It has been noted that it is really time consuming to analyze plate models of tetrahedral solid elements. No relevant options are available for these elements.

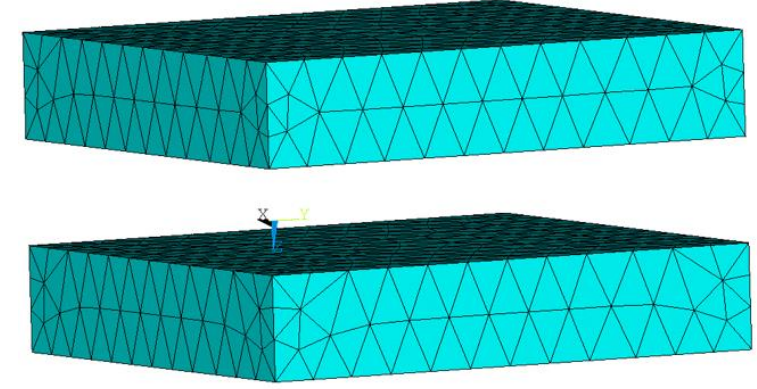

a) Step-1: Standalone meshed plates

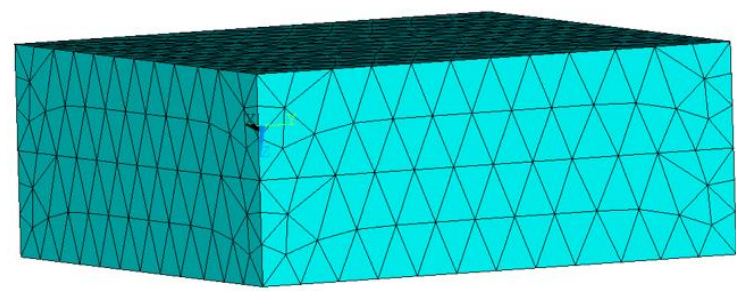

b) Step-2: Glued plates

Fig. 13. Multilayer glued plate modeling 


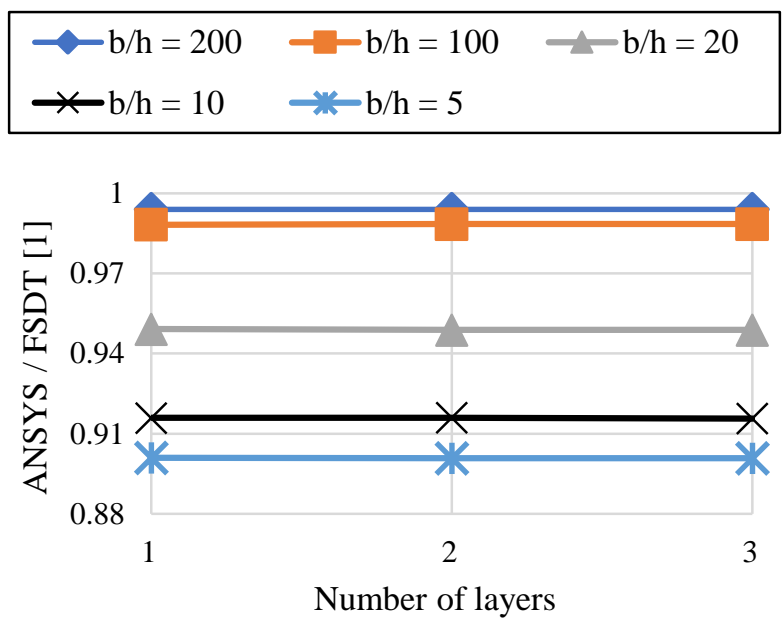

a) Solid187

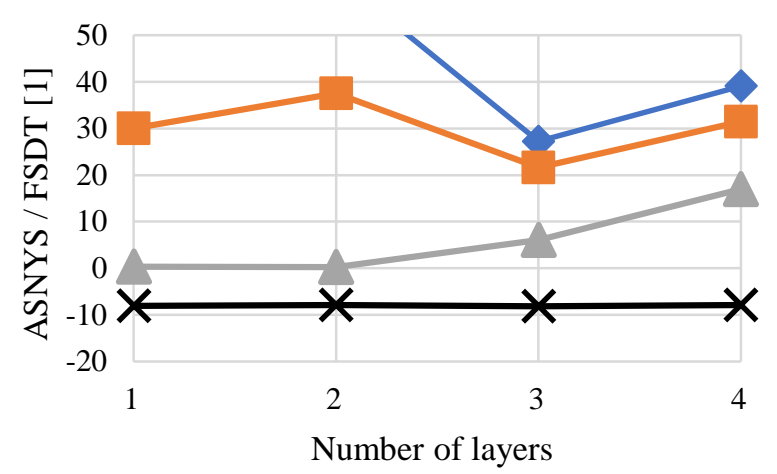

b) Solid285

Fig. 14. ANSYS buckling solutions using tetrahedral solid elements compared to FSDT [1] for various number of layers

\subsubsection{Brick solid elements}

With brick solid elements, number of layers through thickness can be modeled directly by setting the mesh size of the out-of-plane edges as demanded number of layers. Although not needed, gluing many meshed plates together is also a possible way to model multilayer plate with brick solid elements. A third way to model multilayered plate using these elements is by using the SECDATA command of ANSYS, which allows specifying thickness and material for layers through thickness. Relevant options of brick solid elements are examined for the linear eigenvalue analysis, and solutions compared to FSDT solutions are shown in Fig. 15 for Solid185 and Fig. 16 for Solid186 elements. For these analyses, plates are modeled as glued many single-layered plates. Results in Fig. 15 show that plate model of elements Solid185, has to have element technology option set as enhanced strain formulation or simplified enhanced strain formulation (KEYOPT (2) = 2 or 3). Other options for element technology include full integration with B method (KEYOPT $(2)=0$ ), provides wrong results as shown in Fig. 15-b; and uniform reduced integration (KEYOPT $(2)=1$ ), provides unstable results as shown in Fig. 15-c. Stable solution here means that solution does not significantly change anymore by increasing the number of layers.

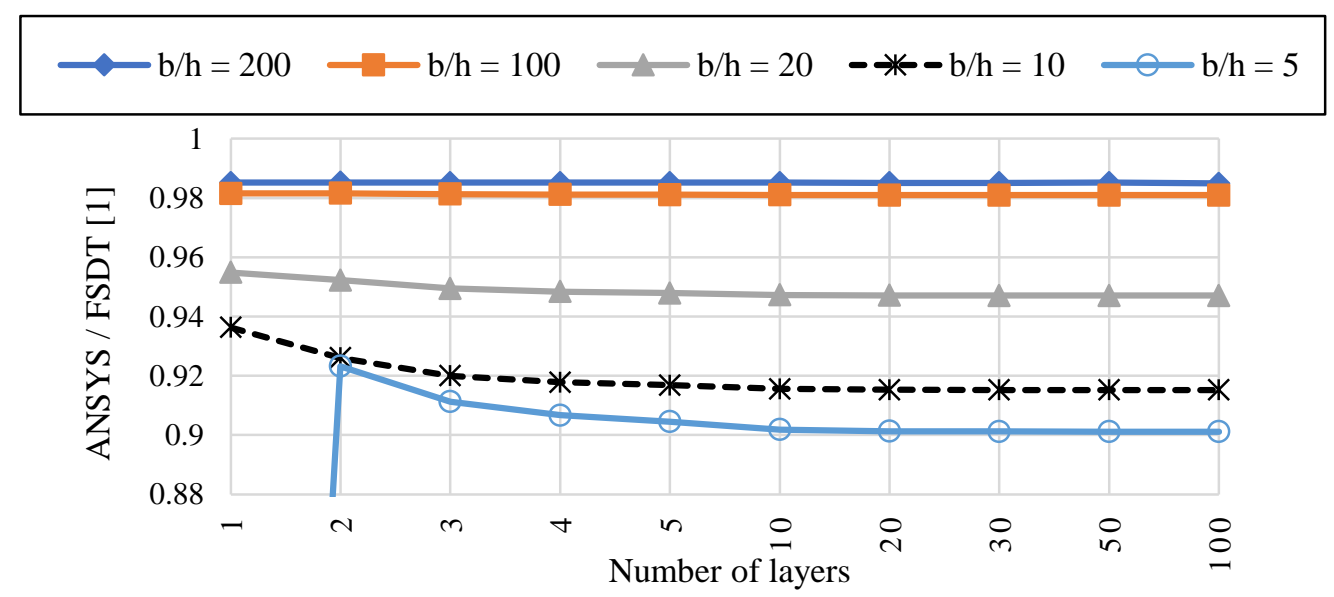

a) Solid185, KEYOPT(2) $=2$ or $\operatorname{KEYOPT}(2)=3$ 


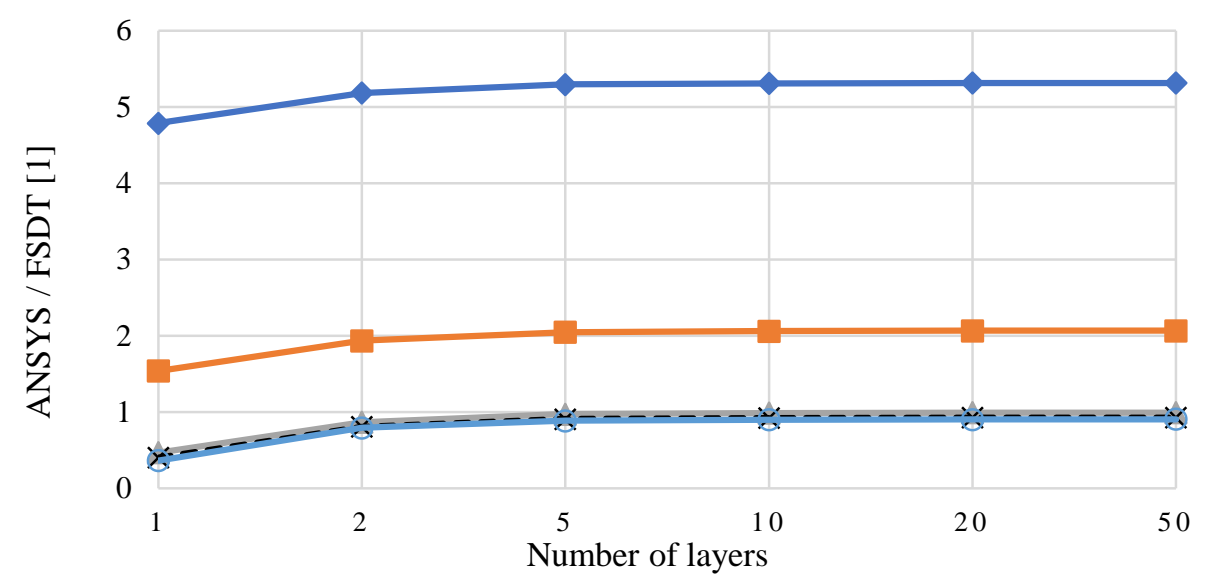

b) Solid185, KEYOPT(2) $=0$

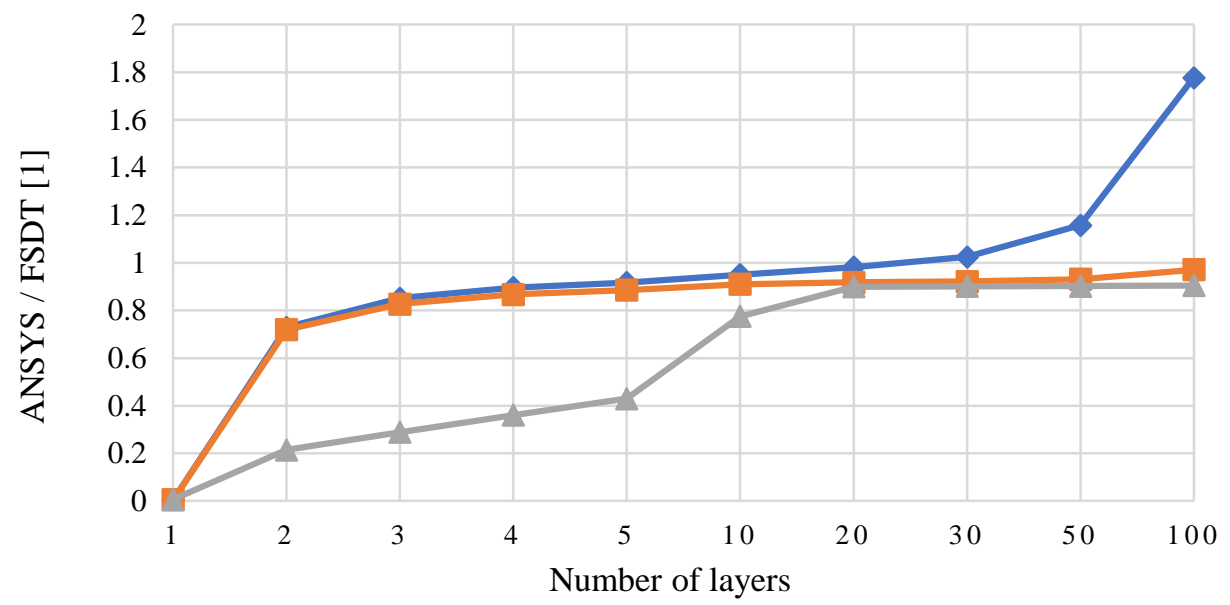

c) Solid185, KEYOPT(2) = 1

Fig. 15. ANSYS buckling solutions using Solid185 elements compared with FSDT [1] for various options of element technology

The second brick solid element is Solid186. It has just two options for element technology to select one of them. The first option is the uniform reduced integration (KEYOPT $(2)=0)$ and the second is the full integration (KEYOPT $(2)=1)$. Both options provide stable solutions for any number of layers exceeds one. Results of buckling loads calculated by ANSYS for plate modeled by Solid186 elements compared to FSDT solutions for both options are shown in Fig. 16-(a and b). 


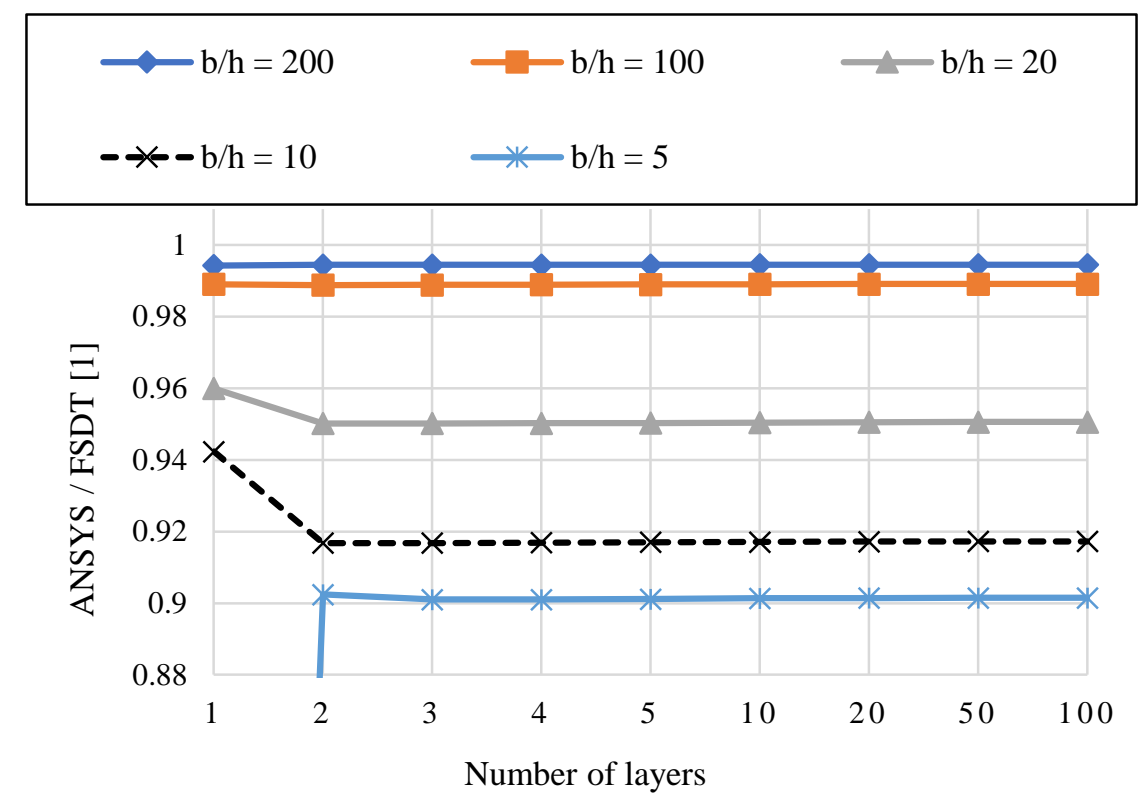

a) Solid186, $\operatorname{KEYOPT}(2)=0$

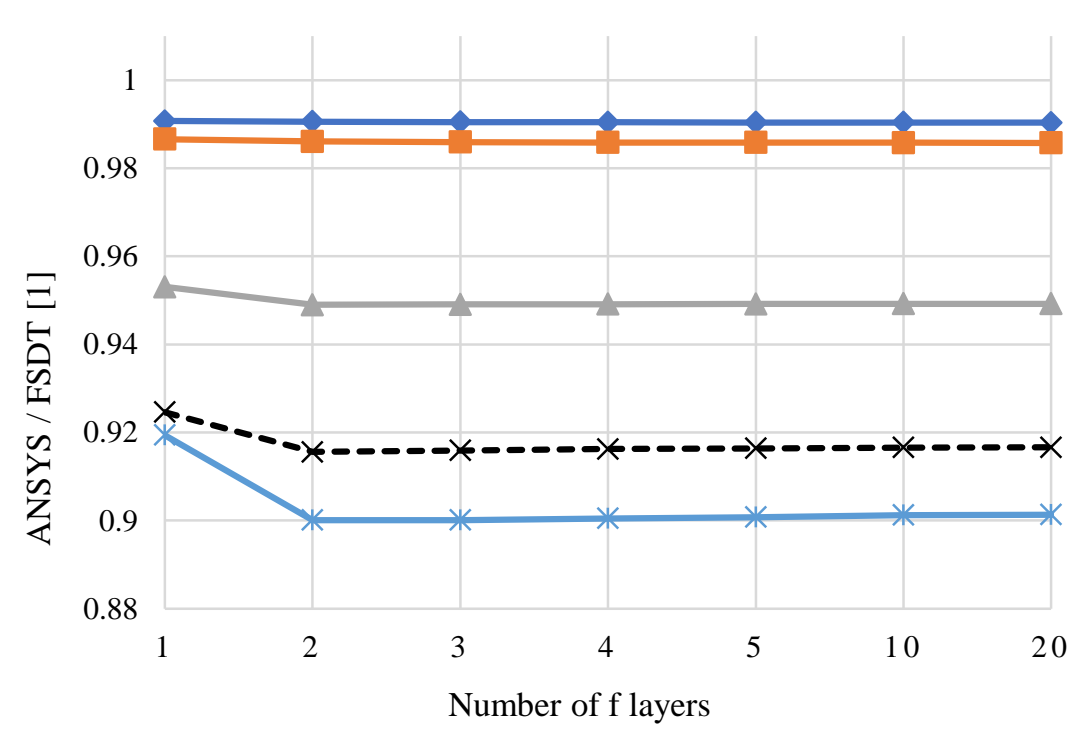

b) Solid186, $\operatorname{KEYOPT}(2)=1$

Fig. 16. ANSYS buckling analysis using Solid186 elements compared to FSDT [1] for various options of element technology

\subsubsection{Solid-shell element}

Solid-shell element Solsh190 is an advanced brick solid element with capabilities to simulate shells more accurately than solid elements. As shown in

Fig. 17, Solsh190 provides better solutions for buckling analysis of thin plates than all other solid elements. Better solutions here means ANSYS solutions closer to FSDT. Here also, plates are modeled as glued thinner plates. It seems that Solsh190 does not provide a stable solution even for large number of layers. Solutions do not stop decreasing as number of layers increases. 


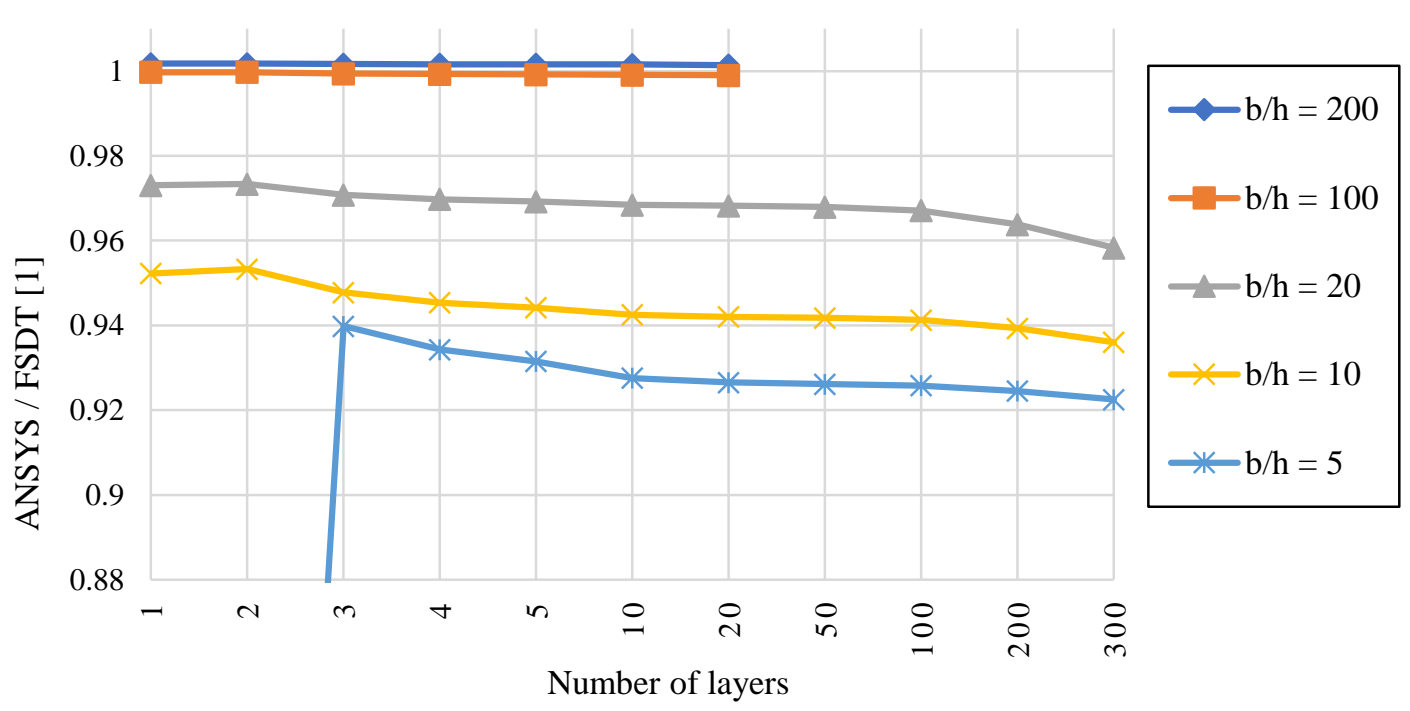

Fig. 17. ANSYS buckling analysis using Solsh190 elements compared to FSDT [1] for various number of layers

Results of using solid models with various number of layers shows that models of solid elements (Solid185, Solid186 and Solid187) and solid-shell element (Solsh190) start to provide stable solutions when enough number of layers and suitable settings are provided. Required number of layers depends on thickness of plate and the elements type used in the model. Thin plates may require just one layer, while thicker plates require more to provide stable solutions. For lower number of layers, plate behaves stiffer, i.e. ANSYS over-predicts the buckling load. For very thick plates, when very low number of layers is used, wrong under-estimated buckling loads result. Even though model of Solid187 elements seems to give stable solutions even when just a single layer is in use, this model is very time consuming in analysis compared with other solid models. For thick plates, solid model of solid-shell element Solsh190 tends to further under-estimate the buckling load with increased number of layers. Using large number of layers with thin plates may cause the analysis to crash or consume long time to end. As shown in

Fig. 17, starting from 20 layers, thin plates of $b / h \leq 100$ cause the analysis to crash and no solution is revealed. Therefore, one have to select number of layers wisely to be in the range that provides accurate results and at the same time does not crash or consume much time. Number of layers to be selected is the number that if increased no significant gain in accuracy is actually obtained.

\section{Boundary conditions effect}

To examine behavior of the plate model with various boundary conditions, shell models of plate under various boundary conditions are analyzed in ANSYS. Thin plates with side-to-thickness ratio (b/h) of 200 are considered, so that plate be comparable to the available analytical solutions based on the classical plate theory (CPT) which presented by Reddy [1]. CPT normally overestimates the buckling load, so it is expected to obtain buckling loads from ANSYS having lower values than those of CPT.

Fig. 18-(a, b and c) show results for various boundary conditions and various aspect ratios.

Fig. 18-a shows results for plates simply supported at two opposite edges while clamped at the other two edges. 
Fig. 18-b shows results for the plates but with one of the clamped edges being free.

Fig. 18-(c and d) show the first and second buckling loads for a plate that is simply supported at three edges while the last is free. In all these analyses, Shell281 models predicts buckling loads lower than those predicted by Shell181 models; and has narrower variation in term of solution accuracy. In addition, it is noticed that both shell models are accurate in predicting buckling load for plates, given that plate is meshed into enough number of elements. That is correct for also higher buckling modes, as shown in

Fig. 18-d, the second buckling load obtained and compared to CPT results; and same behavior and high accuracy observed.

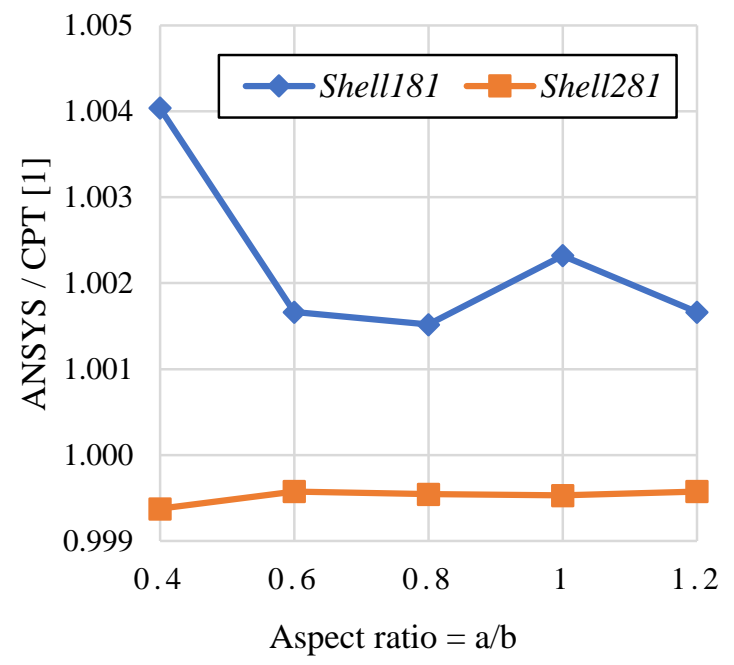

a) SSCC

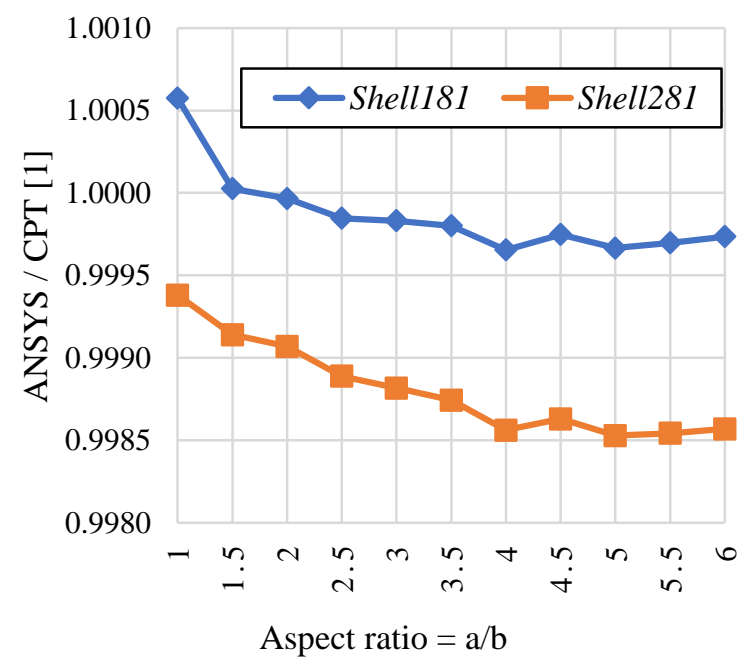

c) SSSF $-1^{\text {st }}$ buckling load

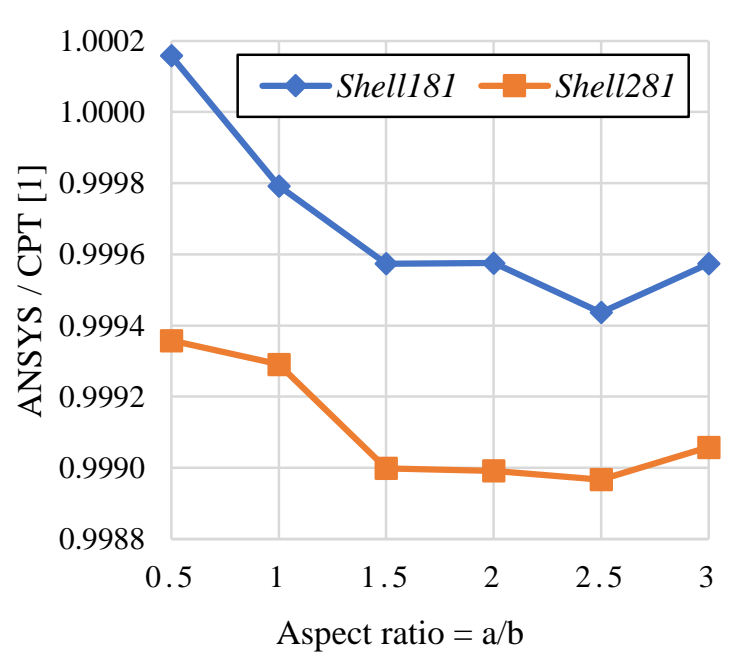

b) SSCF

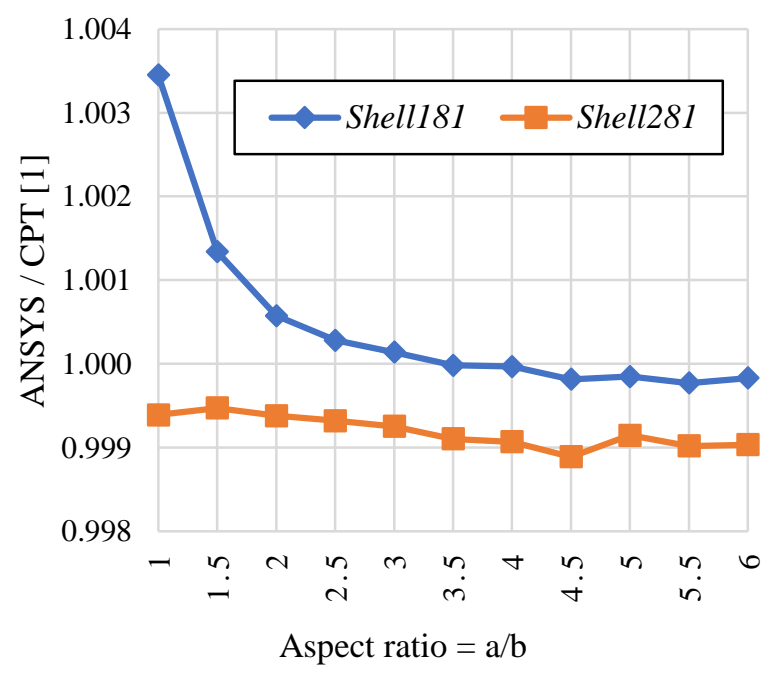

d) SSSF - 2nd buckling load

Fig. 18. ANSYS buckling analysis using shell models compared to CPT [1] for various boundary conditions and aspect ratios

\section{Choosing plate model}


Shell and solid plate models in ANSYS provide different solutions for buckling analysis. Choosing a model for plate buckling analysis in ANSYS depends on the thickness. Shell models provide results that are more accurate for thinner plates, while solid models provide results that are more accurate for thicker ones. However, solid models of solid-shell elements seem to be more accurate than other solid models for both thin and thick plates. Fig. 19 compares between stable results of non-dimensional linear eigenvalue buckling load for various solid and shell models of a square plate under uniform uniaxial pressure, along with solutions based on 3D elasticity theory, FSDT and CPT for plates ranging from thin to thick plates. The 3D elasticity solution is taken from Moslemi [30]. Non-dimensional buckling load $\left(\bar{N}_{c r}\right)$ is calculated as:

$$
\bar{N}_{c r}=N_{c r} \frac{b^{2}}{\pi^{2} D}
$$

$N_{c r}=$ buckling load in $(\mathrm{N} / \mathrm{mm}), \mathrm{b}=$ side length of the plate, $\mathrm{D}$ is the flexural rigidity, calculated as:

$$
D=h^{3} \frac{E}{12\left(1-v^{2}\right)}
$$

$h=$ thickness of the plate, $E$ and $v$ are elasticity modulus and Poisson's ratio of the material of the plate. Solid models of solid elements provide almost the same results for thick plates but different results for thin plates, while solid model of solid-shell element provides a more consistent with solutions based on 3D elasticity theory for thicker plates, and with FSDT for thinner ones.

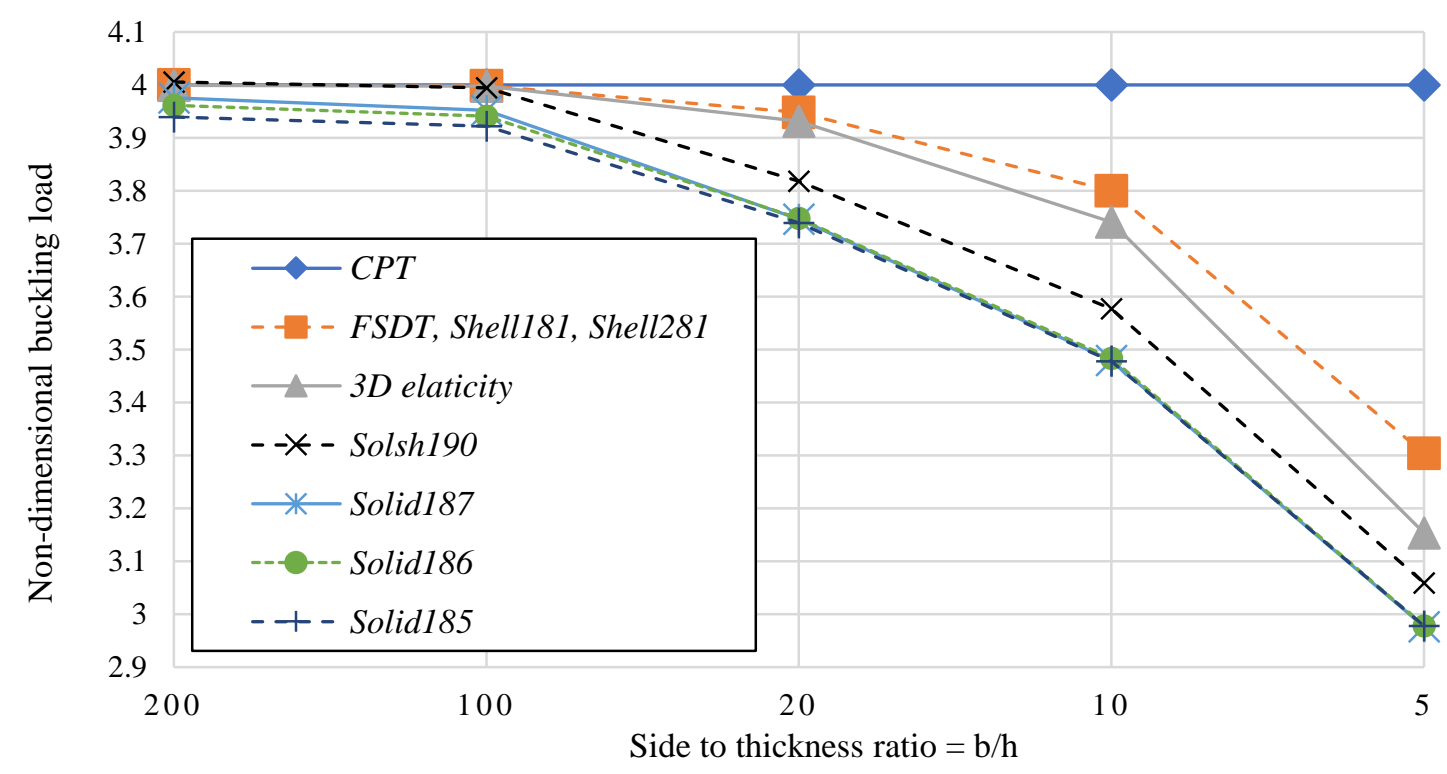

Fig. 19. ANSYS buckling analysis using solid models compared with solutions based on 3D elasticity [30], FSDT [1] and CPT [1] for square plate under uniaxial pressure.

Fig. 20 shows another comparison of linear eigenvalue buckling loads obtained by ANSYS using various solid models along with solutions based on CPT, FSDT and 3D elasticity theory, a square plate under uniform equal biaxial compression. Generally, solid models behave similar to their behavior in the uniaxial case, Fig. 19. Again, models of Solsh190 are the most consistent 
with FSDT for thin plates, and with 3D elasticity solution for thicker plates. Models of solid elements provide similar results for thick plates, but different results for thinner plates, which have significant discrepancy from FSDT, compared to the Solsh190 element. As a conclusion, for thin plates shell models, specifically Shell281, should be used, while for thicker plates solid models of Solsh190 are more accurate.

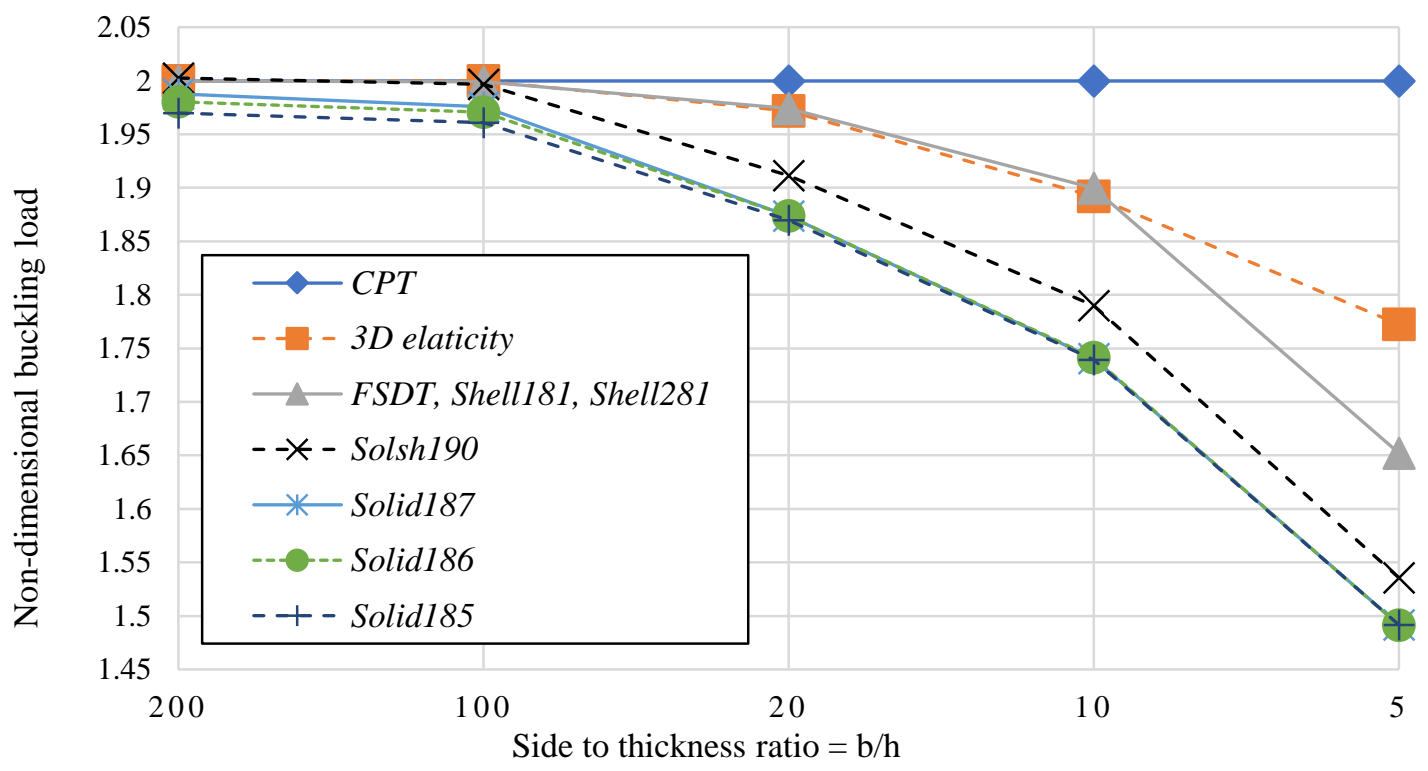

Fig. 20. ANSYS buckling analysis using solid models compared with solutions based on 3D elasticity [30], FSDT [1] and CPT [1] for square plate under equal-biaxial pressure

\section{Conclusion}

Rectangular plate buckling in ANSYS has been presented through comparative studies. Modeling both isotropic and functionally graded rectangular plates, various boundary conditions and meshing of plate structure in ANSYS have been discussed. Various buckling analysis procedures are also discussed. Results obtained from ANSYS are compared with analytical solutions based on various plate theories and 3D elasticity theory.

Meshing plays an important role in obtaining accurate results. Just enough number of elements is needed; much more elements lead to slower analysis with no significant gain in accuracy, while very low number of elements leads to wrong solutions. It is found that selecting plate model depends on the plate thickness. Comparisons in this study show that shell models of rectangular plate have the highest accuracy for thin plates. Models of Shell281 elements are less sensitive to mesh density and it is more accurate compared to the model with Shell181 elements.

Not all solid elements are appropriate for plate buckling analysis; Solid285 provides wrong solutions even with high number of elements. Solid185 has to be implemented with cautious, because for some sets of options it does not provide right solutions. Solid models of appropriate solid elements under-estimate the buckling load for thin plates with different error for each model, while they have the same solutions for thick plates. Solid model of solid-shell elements has accurate solutions close to shell models solutions for thin plates, but for thick plates, its solutions are higher than other solid models, while being significantly lower than shell models and closer to the solutions those based on 3D elasticity theory. 
Because of the wide range of element types and options in ANSYS, having this comparative study facilitates using the software more efficiently in performing buckling analyses on rectangular plates. Future works may include conducting the same comparative study on buckling of plates but with other geometries, e.g. circular, annual, skew and perforated. In addition, buckling of composite plates including functionally graded plates may be investigated more thoroughly in future works, along with thermal and thermo-mechanical buckling analyses.

\section{References}

[1] J. N. Reddy, Theory and analysis of elastic plates and shells, CRC press, 2nd Edition, 2006.

[2] M. R. Eslami, Eslami, and Jacobs, Buckling and Postbuckling of Beams, Plates, and Shells, Springer, 2018.

[3] R. M. Jones, Buckling of bars, plates, and shells, Bull Ridge Corporation, 2006.

[4] K. Bhaskar and T. Varadan, Plates: theories and applications, John Wiley \& Sons, 2014.

[5] C. H. Yoo and S. Lee, Stability of structures: principles and applications, Elsevier, 2011.

[6] K. Mercan; and Ö. Civalek, Modal Analysis of Micro and Nanowires Using Finite Element Softwares, International Journal Of Engineering \& Applied Sciences, 10(4), 291 - 304, 2019.

[7] B. Banerjee, J. Chen, and A. Kathirgamanathan, Comparison of ANSYS elements SHELL181 and SOLSH190, Res. Rep., Univ. of Auckland, New Zealand, 2011.

[8] E. Wang, "Thin-wall structure simulation," presented at the 2006 International ANSYS Conference, 2006.

[9] M. S. Swamy, R. A, S. D, and S. S. Badami, Buckling Analysis of Plate Element Subjected to In Plane Loading Using ANSYS, International Journal of Innovative Research in Science, Engineering and Technology, 4(5), 10, 2015.

[10] T. Subramani and A. Sugathan, Finite element analysis of thin walled-shell structures by ANSYS and LS-DYNA, International Journal of Modern Engineering Research, 2(4), 1576-1587, 2012.

[11] M. Bischoff, "Modeling of shells with three-dimensional finite elements," in Proceedings of the 6th International Conference on Computation of Shell and Spatial Structures. May, 28-31, 2008.

[12] "Introducing APDL," in ANSYS® Release 17.1, Help System, Mechanical APDL, ANSYS Parametric Design Language Guide: ANSYS, Inc.

[13] "SHELL181," in ANSYS® Release 17.1, Help System, Mechanical APDL, Element Reference, Element Library: ANSYS, Inc.

[14] "SHELL281," in ANSYS® Release 17.1, Help System, Mechanical APDL, Element Reference, Element Library: ANSYS, Inc. 
[15] "Performing a Nonlinear Buckling Analysis," in ANSYS® Release 17.1, Help System, Mechanical APDL, Structural Analysis Guide, Buckling Analysis: ANSYS, Inc.

[16] "Command Reference," in ANSYS® Release 17.1, Help System, Mechanical APDL: ANSYS, Inc.

[17] "SOLID285," in ANSYS® Release 17.1, Help System, Mechanical APDL, Element Reference, Element Library: ANSYS, Inc.

[18] "SOLID187," in ANSYS® Release 17.1, Help System, Mechanical APDL, Element Reference, Element Library: ANSYS, Inc.

[19] "SOLID185," in ANSYS® Release 17.1, Help System, Mechanical APDL, Element Reference, Element Library: ANSYS, Inc.

[20] "SOLID186," in ANSYS® Release 17.1, Help System, Mechanical APDL, Element Reference, Element Library: ANSYS, Inc.

[21] "Types of Buckling Analyses," in ANSYS® Release 17.1, Help System, Mechanical APDL, Structural Analysis Guide, Buckling Analysis: ANSYS, Inc.

[22] "SOLSH190," in ANSYS® Release 17.1, Help System, Mechanical APDL, Element Reference, Element Library: ANSYS, Inc.

[23] "Nonlinear Buckling Analysis," in ANSYS® Release 17.1, Help System, Mechanical Applications, Mechanical User's Guide, Analysis Types, Linear Dynamic Analysis Types: ANSYS, Inc.

[24] "Procedure for Eigenvalue Buckling Analysis," in ANSYS® Release 17.1, Help System, Mechanical APDL, Structural Analysis Guide, Buckling Analysis: ANSYS, Inc.

[25] "Eigenvalue Buckling Analysis," in ANSYS® Release 17.1, Help System, Mechanical Applications, Mechanical User's Guide, Analysis Types, Linear Dynamic Analysis Types: ANSYS, Inc.

[26] Y. Miyamoto, W. Kaysser, B. Rabin, A. Kawasaki, and R. G. Ford, Functionally graded materials: design, processing and applications, Springer Science \& Business Media, 1999.

[27] V. Birman, T. Keil, and S. Hosder, "Functionally graded materials in engineering," in Structural Interfaces and Attachments in Biology, vol. 9781461433170: Springer New York, 19-41,2013.

[28] A. H. A. Hassan and İ. Keleş, FGM Modelling using Dummy Thermal Loads, Journal of Selcuk International Science and Technology, 1(10-16), 2017.

[29] B. S. Shariat and M. Eslami, Buckling of thick functionally graded plates under mechanical and thermal loads, Composite Structures, 78(3), 433-439, 2007.

[30] A. Moslemi, B. N. Neya, and J. V. Amiri, 3-D elasticity buckling solution for simply supported thick rectangular plates using displacement potential functions, Applied Mathematical Modelling, 40(11-12), 5717-5730, 2016. 
A. Hassan, N. Kurgan 